\title{
Use and misuse of landscape indices
}

\author{
Harbin $\mathrm{Li}^{1, *}$ and Jianguo $\mathrm{Wu}^{2}$ \\ ${ }^{1}$ USDA Forest Service Southern Research Station, Center for Forested Wetlands Research, 2730 Savannah \\ Highway, Charleston, SC 29414, USA; ${ }^{2}$ Faculty of Ecology, Evolution, and Environmental Science, School of \\ Life Sciences, Arizona State University, Tempe, AZ 85287-4501, USA; *Author for correspondence (e-mail: \\ hli@fs.fed.us)
}

Received 29 May 2001; accepted in revised form 18 August 2003

Key words: Conceptual flaws, GIS and map data, Landscape pattern analysis, Pattern and process, Scale

\begin{abstract}
Landscape ecology has generated much excitement in the past two decades. One reason was that it brought spatial analysis and modeling to the forefront of ecological research. However, high expectations for landscape analysis to improve our understanding and prediction of ecological processes have largely been unfulfilled. We identified three kinds of critical issues: conceptual flaws in landscape pattern analysis, inherent limitations of landscape indices, and improper use of pattern indices. For example, many landscape analyses treat quantitative description of spatial pattern as an end itself and fail to explore relationships between pattern and process. Landscape indices and map data are sometimes used without testing their ecological relevance, which may not only confound interpretation of results, but also lead to meaningless results. In addition, correlation analysis with indices is impeded by the lack of data because of difficulties in large-scale experimentation and by complicated behavior of indices because of their varying responses to changes in scale and spatial pattern. These problems represent significant challenges to landscape pattern analysis, especially in terms of relating pattern to process. In this perspective paper, we examine the underlying problems of these challenges and offer some solutions.
\end{abstract}

\section{Introduction}

Landscape ecology has become one of the most rapidly developing ecological fields worldwide since the mid-1980s, raising excitement and high expectations partly because it brought spatial analysis and modeling to the forefront of ecological research. While landscape ecology emerged in Europe more than half a century ago (Naveh and Lieberman 1984), the past two decades have seen unprecedented developments in theory and practice (Wu and Hobbs 2002). With its fast rising status, landscape ecology continues to diversify in ideas, perspectives, and approaches, becoming a new paradigm in ecology that emphasizes the reciprocal interactions between spatial pattern and ecological processes, scale, and hierarchy (Risser et al. 1984; Turner 1989; Pickett and Cadenasso 1995;
Wu and Loucks 1995; Brandt 1998; Wu and Hobbs 2002).

One of the trademarks of landscape ecology, especially in North America, has been its extensive use of landscape metrics, among numerous methods for spatial pattern analysis (O'Neill et al. 1988; Turner and Gardner 1991; Gustafson 1998). However, after two decades of exciting developments, the ecological understanding derived from landscape pattern analysis has been less than expected. Here, we identify three general types of problems that may be responsible for this unsatisfactory progress (Figure 1): (1) conceptual flaws in landscape pattern analysis, (2) inherent limitations of landscape indices, and (3) improper use of landscape indices. These problems with landscape analysis manifest themselves in many forms, each of which can be fatal to attempts at un- 


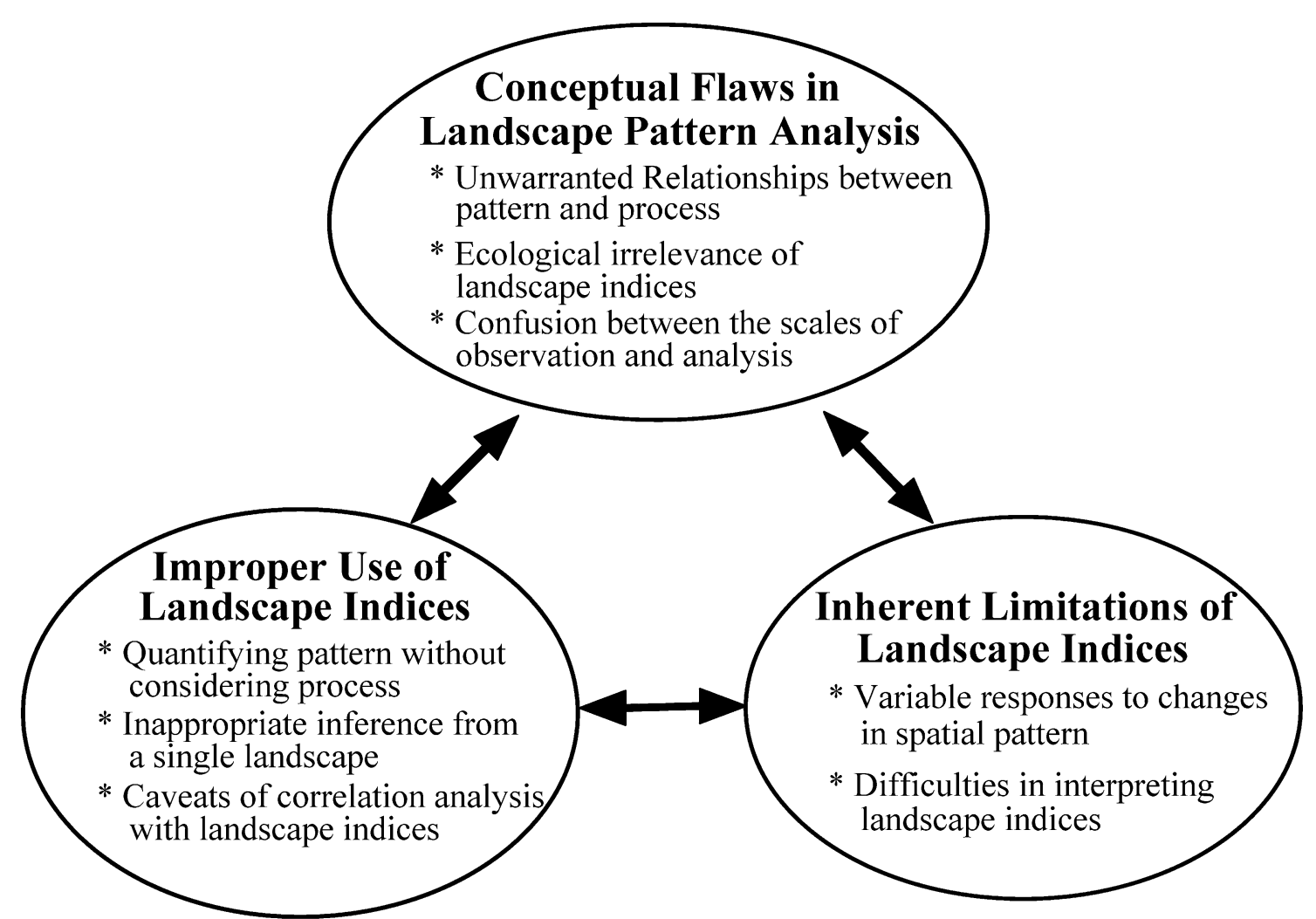

Figure 1. Three types of problems in landscape analysis with pattern metrics: conceptual flaws, improper uses, and inherent limitations of landscape indices. Each type manifests in several forms that overlap with the other types.

raveling the relationships between spatial pattern and ecological processes. The conceptual flaws include: unwarranted relationships between pattern and process, ecological insignificance of landscape indices, and confusion between the scale of observation and the scale of analysis. Two of the common inherent limitations of landscape indices are: variable (and sometimes unpredictable) responses to certain changes in spatial pattern and difficulties in interpreting landscape indices. Failure to deal with any of these flaws and limitations may lead to misuse of landscape indices. Two examples of misuses deserve close attention: quantifying pattern without considering process, and failure to deal with caveats of correlation analysis with landscape indices. Given the necessity and importance of spatial pattern analysis, these issues must be addressed promptly and adequately.

The main objectives of this perspective paper are to analyze the nature of, and to seek possible solutions to, the problems in landscape pattern analysis using landscape metrics. These three types of prob- lems are closely related and at times even overlap (Figure 1), but we will discuss them separately for the clarity of presentation and examine them from different perspectives. We do not pretend that we know the solutions to all the problems discussed here, but we believe that identifying these problems is a critical first step forward. Although some of the issues are known to many, others are not well understood. An in-depth analysis should help better understand these problems, and thus improve the application of landscape pattern analysis.

\section{Conceptual flaws in landscape pattern analysis}

Unwarranted relationships between pattern and process

Many landscape ecological studies have focused on the description and quantification of spatial patterns and, to a lesser degree, on how they affect processes (Flather and Sauer 1996; Turner et al. 2001). A fun- 
damental pursuit in landscape ecology (or science in general) is to search for relationships between pattern and process that explain why the world is the way it appears and how it works (Cale et al. 1989). Ecological processes often not only affect but also are affected by the spatial patterns of landscapes (Turner 1989; Pickett and Cadenasso 1995). For example, a disturbance like fire provides one of the primary mechanisms for generating vegetation pattern, while vegetation pattern in turn affects the disturbance regime. Thus, landscape ecologists may be interested in how vegetation distribution (pattern) is generated by the fire regime (process) and to what extent fire spread can be inferred from vegetation distribution. These are appropriate questions because vegetation pattern and the fire process have an interactive relationship. In this pattern and process principle, pattern and process are assumed to be interactive (reciprocal): process creates, modifies, and maintains pattern, whereas pattern constrains, promotes, or neutralizes process. This principle provides the foundation for spatial pattern analysis.

Such interactive relationships seem to have become a background assumption in many, if not most, landscape ecological studies without a critical scrutiny. However, this assumption may not be valid when emphasis on spatial pattern in landscape ecology changes the connotation of the term "pattern" and disassociates it from process in the pattern and process principle. In other words, spatial pattern (narrowly defined as distributional or mosaic structure of landscape elements) does not necessarily have any relationship with some ecological processes of interest. Failure to realize the existence of non-interactive relationships may cause conceptual flaws in landscape analysis. Thus, some form of "proof of existence" is needed to demonstrate or reliably infer a reciprocal or one-directional relationship between spatial pattern and process. Simple analysis may be used to establish necessary (but not sufficient) conditions for the "proof of existence."

First, if a process of interest does not produce the spatial pattern, the process should not have any inherent relationship to the spatial pattern, and interactive relationships should not be assumed. "One-directional effects" of spatial pattern on ecological processes may still exist, but additional information is required to confirm them and different interpretation of results may apply. An example of such onedirectional relationships is that vegetation pattern (habitat distribution) affects but is not generated by bird population dynamics. Second, if a process is non-spatial, effects of spatial pattern on the process are unlikely to occur because spatial pattern is not a critical factor to the non-spatial process. In this situation, the value of spatial pattern analysis and spatially explicit modeling may be limited. An example of non-spatial processes is the overall primary productivity of ecosystems. The primary productivity may change at different locations in a landscape. However, this change may not be caused by spatial pattern per se, but merely reflect distributional changes of the critical factors (e.g., soil nutrients, moisture). Third, if the pattern and the process do not operate at similar rates and in the same domains of spatial scales, they cannot have an interactive relationship ( $\mathrm{Wu}$ 1999). This assertion is consistent with the space-time decomposition principle that is essential to hierarchy theory (Allen et al. 1984; O’Neill et al. 1986; Wu 1999). Inadequate understanding of the scale-dependent relationship between pattern and process may have contributed to confusion in landscape ecology. For example, few would assume that centimeter-scale grass clumping patterns could alter the pathways of eagles in a similar way that these fine-grained patterns influence the movement of beetles. The work of ecologists would be easier if they could extrapolate biochemists' understanding of Rubisco's carbon-fixing mechanisms to the global scale in predictions of biospheric responses to elevated $\mathrm{CO}_{2}$. Such extrapolations from enzyme molecules to the planet would be unrealistic due to scale separations of several orders of magnitude in space and time.

\section{Ecological irrelevance of landscape indices}

If landscape indices are ecologically relevant and reflect important attributes of spatial pattern, they can functionally link the dynamics of ecological processes to landscape structure (e.g., Wiens et al. 1993). However, ecological relevance of landscape indices is more often presumed than established, with inadequate supporting empirical evidence in the literature. In the absence of such evidence, landscape indices are mathematical constructs that have no inherent ecological meanings. The validity of landscape analysis will increase if indices are selected according to their ecological relevance rather than the convenience of computer programs. While ecology is emphasized here, the same arguments should apply to other disciplines 
(e.g., geography, sociology) in which landscape indices are used.

Notwithstanding the value of indices in spatial pattern recognition, indiscriminate use of landscape indices hinders efforts to establish relationships between spatial pattern and process, especially in correlation analysis. Exploratory analysis always plays a valuable role in science. However, the ultimate goal of exploratory analysis is to generate causal explanations and hypotheses that explain why the landscape is as it appears (Pickett et al. 1994). Doing so involves identification and development of those ecologically relevant indices that have close associations with ecological processes. For example, evaluating wildlife habitats requires the development of indices that can be related to food (e.g., foraging efficiency), cover (e.g., shelters for energy conservation), reproduction (e.g., nesting sites), and other population processes (e.g., dispersal). To ensure ecological relevance, these variables of species habitat requirements should be incorporated into map data used in spatial pattern analysis (e.g., Li et al. 2000).

\section{Confusion between the scales of observation and analysis}

Understanding the role of scale in landscape analysis requires distinguishing between the scale of observation, at which the natural world is translated into data, and the scale of analysis, at which patterns are revealed from the data ( $\mathrm{Li}$ and Reynolds 1995). The scale of observation is determined by the characteristics of the system studied, the questions asked, and the data collection protocols used (e.g., platforms and sensor types for remote sensing data, sampling schemes for field survey data). Once the data are collected, however, the scale of observation is an inherent property of the data set. What can be and is often changed is the scale of analysis, which is superimposed on the data. The scale of analysis is determined by the original scale of observation and the methods of data transformation, including aggregation, magnification, and resampling (Figure 2).

To adequately quantify the spatial heterogeneity and detect characteristic scales of landscapes, landscape indices should be computed at multiple scales. Difficulties in collecting data at multiple scales of observation have forced most studies of scale effects to concentrate on the scales of analysis. A common approach is to obtain data at one scale of observation, artificially change the grain or extent of the map data through rescaling, and perform analysis and modeling with the newly generated multi-scale data (Gardner et al. 1987; Turner et al. 1989; Wu 2000; Wu 2003; Saura and Martinez-Millan 2001; Wu et al. 2002). Changing scale by manipulating data can be a surrogate for observing the landscape directly with two or more sensors (or sampling schemes) of different resolutions. However, if the surrogate fundamentally differs from the direct observation, the rescaling results represent artifacts of data manipulations and may not be used to infer trends from the scale of observation. Our understanding of the effects of "rescaling data" is still rudimentary although more insight may be gained from a synthesis of numerous studies carried out in geography and remote sensing (e.g., Openshaw 1984; Justice et al. 1989; Jelinski and Wu 1996; Bian and Butler 1999; Wu 2003). Regardless of how data are changed subsequently, the effects and limitations of the scale of observation may still remain. One must be cautious in interpreting results from rescaled data, and be aware that patterns and scales revealed in such analyses may not correspond to those in the real landscapes, or not even to those captured in the data set on which the rescaling is based.

\section{Inherent limitations of landscape indices}

Variable responses to changes in spatial pattern

Landscape indices may display variable responses to certain changes in spatial pattern (Haines-Young and Chopping 1996; Turner et al. 2001). Such limitations make result interpretation difficult and compromise the effectiveness of correlation analysis because they cannot capture or distinguish some of the fundamental changes of landscapes in many situations. Three examples of inherent limitations of landscape indices are demonstrated below.

Landscape indices may not differentiate landscapes with qualitative changes because of their insensitivity and non-uniqueness (Haines-Young and Chopping 1996; Turner et al. 2001). Interpretation of results of landscape analysis must consider the nature of landscape changes. For example, evenness would remain unaffected when forest landscapes change into urban landscapes in the manner depicted in Figure 3A (Table 1). This is not surprising because evenness is calculated with proportions. However, one may question the value of landscape indices when spatial indi- 


\section{(Rescaling) \\ Original Map $\longrightarrow$ New Map}
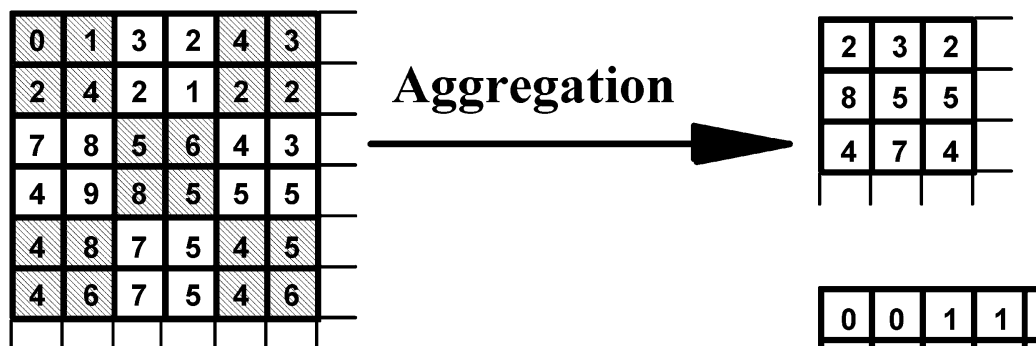

\begin{tabular}{|l|l|l|l|l|l|l|l|l|l|l|l|l}
\hline 0 & 0 & 1 & 1 & 3 & 3 & 2 & 2 & 4 & 4 & 3 & 3 & \\
\hline 0 & 0 & 1 & 1 & 3 & 3 & 2 & 2 & 4 & 4 & 3 & 3 & \\
\hline 2 & 2 & 4 & 4 & 2 & 2 & 1 & 1 & 2 & 2 & 2 & 2 & \\
\hline 2 & 2 & 4 & 4 & 2 & 2 & 1 & 1 & 2 & 2 & 2 & 2 & \\
\hline 7 & 7 & 8 & 8 & 5 & 5 & 6 & 6 & 4 & 4 & 3 & 3 & \\
\hline 7 & 7 & 8 & 8 & 5 & 5 & 6 & 6 & 4 & 4 & 3 & 3 & \\
\hline 4 & 4 & 9 & 9 & 8 & 8 & 5 & 5 & 5 & 5 & 5 & 5 & \\
\hline 4 & 4 & 9 & 9 & 8 & 8 & 5 & 5 & 5 & 5 & 5 & 5 & \\
\hline 4 & 4 & 8 & 8 & 7 & 7 & 5 & 5 & 4 & 4 & 5 & 5 & \\
\hline 4 & 4 & 8 & 8 & 7 & 7 & 5 & 5 & 4 & 4 & 5 & 5 & \\
\hline 4 & 4 & 6 & 6 & 7 & 7 & 5 & 5 & 4 & 4 & 6 & 6 & \\
\hline 4 & 4 & 6 & 6 & 7 & 7 & 5 & 5 & 4 & 4 & 6 & 6 & \\
\hline & & & & & & & & & & & &
\end{tabular}

\begin{tabular}{ll|l|l|l|l|l|l}
\hline 0 & 1 & 3 & 2 & 4 & 3 & \\
\hline 2 & 4 & 2 & 1 & 2 & 2 & \\
\hline 7 & 8 & 5 & 6 & 4 & 3 & \\
\hline 4 & 9 & 8 & 5 & 5 & 5 & \\
\hline 4 & 8 & 7 & 5 & 4 & 5 & \\
\hline 4 & 6 & 7 & 5 & 4 & 6 & \\
\hline & & & & & &
\end{tabular}

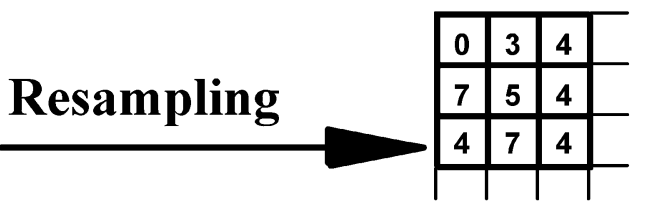

Figure 2. Three examples of data transformation during landscape analysis: majority-rule based aggregation, zooming (or magnification), and systematic resampling of categorical map data. In the aggregation procedure, the value of a pixel in the new map is determined by the patch type with the most pixels within a moving window in the old map; a random number is used to break a tie. Zooming is to replicate the same pixel multiple times, which increases the number of pixels in the map, but not its information content. Resampling is to create a new map by sampling an existing map systematically or randomly. Because resampling in this case effectively increases the grain size of the map, it can be considered a kind of aggregation that does not use the majority rule.

ces like contagion and fractal dimension of patch shape also fail to capture the clear spatial changes in the two maps (Figure 3A; Table 1). Such failure should be expected because, like evenness, contagion and fractal dimension are calculated with the aggregated information of proportions of patch sizes and edges that does not consider the association of proportions with patch types. As for the patchiness index, its higher value for the urban landscape is due to the higher dissimilarity values (i.e., contrast) assigned to edges between an urban patch and a patch of any other types.

Landscape indices may be sensitive to the level of detail in categorical map data that is often determined by the schemes (or criteria) used for map classification (Figure 3B; Table 1; Wickham et al. 1997; Turner et al. 2001). This is because the inclusion or exclusion of patch types produces distinctive differences in the landscape mosaic (i.e., the number of recognized patch types). Thus, the same landscape is represented rather differently when different classification 
A. Qualitative Change of Landscapes

1. Forest Landscape

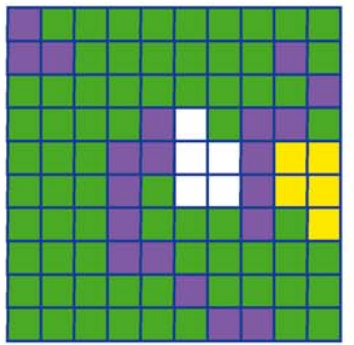

$70 \%$

$20 \%$

$5 \%$

$5 \%$
2. Urban Landscape

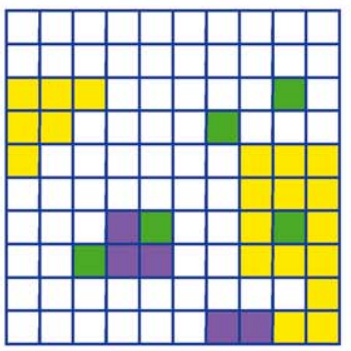

Forest

Wetland

Agriculture

Urban

\begin{tabular}{|r|}
$\square \quad \mathbf{5 \%}$ \\
$\square \quad \mathbf{5 \%}$ \\
$\square \quad \mathbf{2 0 \%}$ \\
$\square \quad \mathbf{7 0 \%}$ \\
\hline
\end{tabular}

B. Classification Change of Landscapes

1. Low Level of Detail

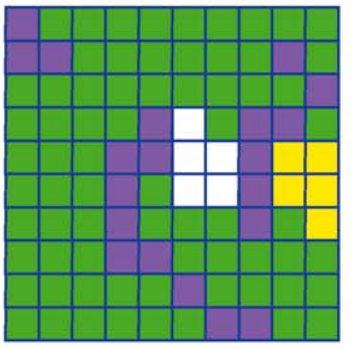

$\square$ Forest

$\square$ Wetland

Agriculture

$\square$ Urban
2. High Level of Detail

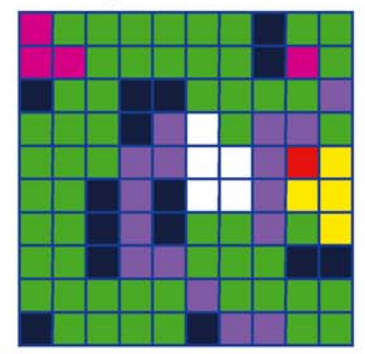

$\square$ Pine $\square$ Hardwood

$\square$ Riverine $\square$ Carolina Bay

$\square$ Crops

Urban

C. Functional Difference of Landscapes

1. Vegetation Map
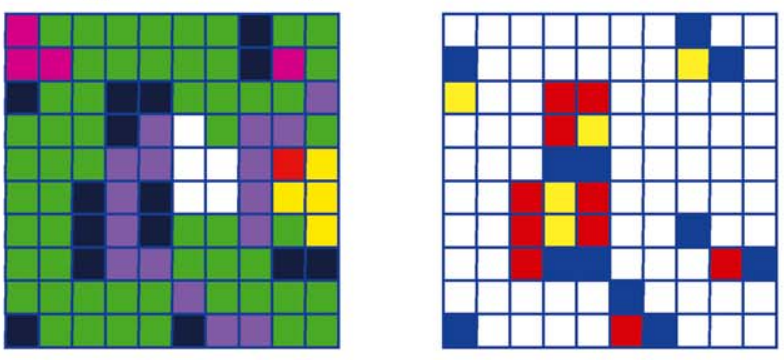

Acadian Flycatcher Bachman's Sparrow

$\square$ Pine $\square$ Hardwood
$\square$ Riverine $\square$ Carolina Bay
$\square$ Crops $\square$ Pasture
$\square$ Urban

2. Habitat Rank Maps

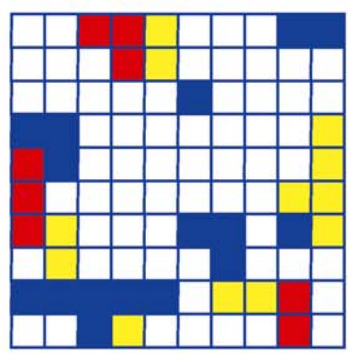

Optimal

Suitable

Marginal

Non-Habitat 
Figure 3. Examples of failures of indices to reflect landscape changes (Table 1); A. Two landscapes with qualitative differences may yield the same values of some landscape indices. In this hypothetical situation, a forest landscape (A1: 70\% forest, $20 \%$ wetland, $5 \%$ agriculture, and 5\% urban) changes into an urban landscape (A2: $5 \%$ forest, 5\% wetland, 20\% agriculture, and 70\% urban). However, the information indices (i.e., diversity, evenness, dominance) cannot capture such changes at all, whereas spatial indices like contagion and fractal dimension also fail in this case; B. Two classification systems with different levels of detail may be applied to the same landscape, resulting in different map complexities and different values of landscape indices, even though there is no real change in the landscape. At a coarse level of detail, one may recognize four patch types: forest, wetland, agriculture, and urban (B1). However, at a fine level of detail, one may choose to recognize significant differences within a type, resulting in seven patch types: pine forest, hardwood forest, riverine wetlands, isolated wetlands, crop fields, pastures, and urban (B2). Obviously, most landscape indices will yield different values when different classification systems are used; C. A GIS vegetation map (C1) cannot be used to characterize functional difference of the landscape because maps like this are often ecologically irrelevant to a particular study. However, the vegetation map can be translated into habitat rank maps (C2), based on the differential habitat requirements by two species of interest: Acadian Flycatcher (Empidonax virescens), a tree nesting, Neotropical migratory bird that requires moist deciduous forest with a moderate understory and generally near a stream, and Bachman's Sparrow (Aimophila aestivalis), a ground nesting resident bird that breeds in open (young) pine forest (Hamel 1992, Li et al. 2000). Indices calculated from the habitat rank maps may represent habitat quality of the landscape for different wildlife species.

Table 1. Values of landscape indices calculated for the maps in Figure 3. The indices are the same as those used in Li and Reynolds (1994, 1995).

\begin{tabular}{|c|c|c|c|c|}
\hline Map & Evenness & Contagion & Fractal & Patchiness \\
\hline Forest Landscape (A1) & 0.628 & 0.289 & 1.494 & 0.309 \\
\hline Urban Landscape (A2) & 0.628 & 0.290 & 1.497 & 0.320 \\
\hline Low Level of Detail (B1) & 0.628 & 0.289 & 1.494 & 0.309 \\
\hline High Level of Detail (B2) & 0.699 & 0.382 & 1.578 & 0.573 \\
\hline Vegetation $(\mathrm{C} 1)$ & 0.699 & 0.382 & 1.578 & 0.573 \\
\hline Habitat Rank for Acadian Flycatcher (C2a) & 0.623 & 0.199 & 1.538 & 0.381 \\
\hline Habitat Rank for Bachman's Sparrow (C2b) & 0.761 & 0.168 & 1.576 & 0.528 \\
\hline
\end{tabular}

schemes are used. The pitfall of such manipulation of map data is that the output captures changes that have not taken place either structurally or ecologically. A solution to this problem is to assure the ecological relevance of map data by determining how much detail to recognize and what scale to use according to the phenomenon and the objectives of the study.

Landscape indices may also be insensitive to functional attributes of landscapes (Wiens 1989). One example of such attributes is the habitat suitability of a landscape as viewed by wildlife species (Figure 3C; Table 1). Because different species have unique habitat requirements, habitat quality can vary dramatically on the same landscape, and should not be represented by landscape indices unless specific attributes are explicitly expressed in map data (Harris and Sanderson 2000; Li et al. 2000). Understanding how landscape pattern affects the population dynamics of two different species requires translation of vegetation maps into habitat suitability maps that incorporate functional differences into landscape analysis. Li et al. (2000) found that GIS maps of forest landscapes with all "natural boundaries" often lack ecological relevance for evaluating habitat quality because no single map can represent the diverse habitat requirements of many wildlife species. To generate landscape maps that are relevant for spatial analysis of habitat quality, we recommend an approach that combines landscape and species habitat evaluation. The approach involves creation of a habitat rank map for each target species (or a guild) by aggregating adjacent patches with the same habitat rank after ranking each patch as optimal, suitable, marginal, and non-habitat (Hamel 1992; Li et al. 2000). The use of habitat rank maps strikes a balance between species-specific information and landscape analysis, and reflects a landscape's suitability for different species.

\section{Difficulty in interpreting indices}

After two decades of extensive research, interpreting indices remains difficult because the merits and caveats of landscape metrics remain poorly understood $(\mathrm{Li}$ and Reynolds 1994; Gustafson 1998; Hargis et al. 1998; Wu 2000; Turner et al. 2001). What an index really measures is uncertain even when the analytical aspects of most indices (e.g., information indices, fractal dimension) are quite clear ( $\mathrm{Li}$ and Reynolds 1994). For example, changes in fractal dimension may be difficult to interpret because multiple factors 
simultaneously affect its value and because the several formulas of fractal dimension produce a wide range of results (Lovejoy 1982; Gardner et al. 1987; Krummel et al. 1987; Milne 1991; Dale 1999). In addition, even though changes in spatial pattern metrics can reflect significant changes in landscape function and integrity, specific thresholds are rarely known (Turner et al. 2001, p. 329-330). Statistical methods that can be used to define such thresholds need to be explored. Resolving any of the problems discussed in this paper would make it easier to interpret the results of landscape analysis. The best solution is that landscape ecologists understand not only the methods of spatial pattern analysis, but also the concepts on which the methods are based (Dale 1999).

The discipline of landscape ecology needs better, more effective indices, both in their ability to capture different aspects of spatial pattern and in their ease of interpretation. Specific improvements may be achieved in three areas. First, additional studies are needed to determine which combination of indices is most effective in a particular situation (Li and Reynolds 1994; Riitters et al. 1995; Haines-Young and Chopping 1996; Hargis et al. 1998; O’Neill et al. 1999). Most indices represent more than one aspect of spatial pattern, which adds to the difficulty in interpreting their results, while many studies have shown that a single index provides inadequate information about spatial pattern (Li and Reynolds 1994; Riitters et al. 1995; O'Neill et al. 1999). Li and Reynolds (1994) suggested a group of indices, each of which is designed to measure exactly one component of spatial pattern, including landscape composition, spatial arrangement of patches, contrast between neighboring patches, anisotropy, and connectivity. Riitters et al. (1995) also identified six groups (aspects) of landscape measures that show low redundancy and explain much of the variation in landscape structure when used together. Second, it is much easier to interpret values of an index if the index is relative, ranging from 0 to 1 (or -1 to +1 ) and if the minimum and maximum values of the index have clear ecological meanings. For most measures of spatial pattern, help is available in the form of standardization operations (Hurlbert 1971). Third, the ecological meanings of most landscape indices deserve further scrutiny. Emphasis should be placed on indices that directly measure processes or have built-in relationships with ecological processes (e.g., O’Neill et al. 1999; Ludwig et al. 2000).

\section{Improper use of landscape indices}

\section{Quantifying pattern without considering process}

Quantification of spatial pattern has dominated landscape ecological research, particularly in North America, since the mid-1980s (O'Neill et al. 1988; Turner and Gardner 1991), primarily because pattern recognition is one of the cornerstones in scientific understanding of nature (Pickett et al. 1994). However, the progress of landscape ecology suffers if quantifying spatial pattern is treated as an end itself, rather than as the first step to understanding ecological processes. Spatial pattern analysis is of limited value if not used to explain structural changes in landscapes and predict how they influence ecological processes.

If better understood and practiced, landscape pattern analysis can play useful roles in theory and practice of landscape ecological research (O'Neill et al. 1988; O’Neill et al. 1999; Turner 1990; Li and Reynolds 1994; Gustafson 1998; Turner et al. 2001): (1) comparing different systems or the same system at different times, (2) monitoring large-scale change to ensure that magnitudes and rates of vital ecological changes are determined in a timely fashion, and (3) providing alternatives that convert maps and other spatial data into formats that are more useful and easier to understand. However, even these uses presume that a particular quantitative description of spatial pattern is of ecological importance, a presumption that landscape ecologists must verify by demonstrating a close relationship between spatial pattern and ecological process (Gustafson 1998; Turner et al. 2001).

\section{Caveats of correlation analysis with landscape indices}

Correlation analysis is an effective tool for establishing relationships and then subjecting them to further evaluations of causal explanation and testing (Pickett et al. 1994). However, correlation analysis with landscape indices can be problematic when the conceptual flaws and inherent limitations discussed in the previous sections are ignored. The most critical among them are the ecological irrelevance of landscape indices or map data and the variable responses of indices to changing landscape patterns. The consequence of ignoring these flaws and limitations is that results in statistical correlation are likely 
to have no biological meaning. Specifically, correlation analysis is likely to be misused in situations that involve changing scales, complex indices, and studies with a single landscape.

Scale must be considered in correlation analysis because most landscape indices are sensitive to changing grain and extent (Turner et al. 1989; Wickham and Riitters 1995; Wu 2000; Wu 2003). Ecological systems are often hierarchically structured (O’Neill et al. 1986; Urban et al. 1987; Wu 1999), with different patterns and processes taking place on certain "characteristic" or "threshold" scales. If landscape analysis is done only at a single scale that does not match the characteristic scale of the phenomenon of interest, the result may be a failure to detect pattern in a landscape even though pattern exists, or the "manufactured pattern" when none exists. On the other hand, if landscape analysis is done with data from multiple scales, scale itself may need to be recognized explicitly as a covariate. In general, to adequately quantify the spatial heterogeneity and detect characteristic scales of landscapes, spatial pattern indices should be computed at multiple scales. Multiscale analysis methods (e.g., fractal dimension, semivariogram, quadrat variance techniques) are preferred, although none is guaranteed to be effective for a particular landscape (Li and Reynolds 1994; Dale 1999; Wu 2000; Wu 2003).

Many of landscape indices are complex, having either nonlinear formulation or multiple inputs (components) or both (e.g., evenness, contagion, fractal dimension). These complex indices should be avoided in correlation analysis because their nonlinear formulation and multiple inputs make them more likely to have mixed responses to changing pattern, scale and classification scheme (O'Neill et al. 1988; Li and Reynolds 1993; Li and Reynolds 1994; Riitters et al. 1995; Wu 2000). Their complex behavior underscores the interpretation problems that compromise the effectiveness of correlation analysis. Instead, simple metrics measured directly from fields or maps (e.g., patch size, edge, inter-patch distance, proportion) are more likely to generate meaningful inferences.

Many empirical landscape studies apply spatial pattern analysis to just one landscape. While such studies are useful because they tackle problems at relevant scales (Carpenter 1992; Carpenter 1996; Oksanen 2001), the validity of conducting correlation analysis and making statistical or ecological inferences is seriously compromised under such conditions (Hurlbert 1984). Pseudoreplication has been recognized as an obstacle to large-scale experiment and analysis (Hurlbert 1984; Hargrove and Pickering 1992; but see Oksanen 2001). When only one landscape is involved, no correlation analysis or statistical inference can be done because using the spatial pattern of the landscape as a variable (e.g., an index) reduces the analysis to a single data point, which represents the worst situation of pseudoreplication - no replication at all. Research that uses multiple landscapes is needed for establishing reliable relationships between pattern and process at the landscape scale, even though difficulties involved in conducting replicated sampling and experiment at large scales will remain. Although it is not a solution for pseudoreplication, simulation experimentation can be extremely valuable when landscape dynamics can be studied with different scenarios and sufficient replications (e.g., Gardner et al. 1987; Li and Reynolds 1994).

Clearly, correlation analyses are more fruitful if causal explanations for the relationships (e.g., constraints, interactions, mechanisms) are identified beforehand. Calculating numerous landscape indices for correlation analysis without a clear understanding of spatial patterns and processes involved is a questionable strategy because statistical relationships without ecological meanings can be useless or even misleading.

\section{Concluding remarks}

We have identified and discussed three groups of issues - the conceptual flaws in landscape pattern analysis, the inherent limitations of landscape indices, and the improper use of these indices - that may have caused misuse and reduced the usefulness of landscape indices, severely hindering the progress of landscape pattern analysis. Our list of the issues is by no means exhaustive. Most critical among the seven issues discussed here are the disconnection of pattern from process, the ecological irrelevance of landscape indices and map data, the variable responses of indices to pattern changes, and the misuse of correlation analysis. We rely heavily on deductive reasoning, even though empirical analysis may help strengthening our arguments.

We suggest that a serious rethinking of "why landscape pattern analysis is used" may facilitate the search for resolutions on "how landscape pattern analysis should be used." Without theoretical guidance, landscape ecologists are often overwhelmed by 
numerous indices and spatial statistical methods, as well as by increasing volumes of GIS and remote sensing data. The ultimate goal of landscape pattern analysis should be to achieve better explanations and predictions of ecological phenomena based on established relationships between pattern and process. All other research endeavors - such as spatial pattern detection, quantification, comparison, correlation, and monitoring - should be conducted only if they help achieve this goal. We fully agree with Levin (1992), who promoted detecting and describing patterns before seeking "to discover the determinants of pattern, and the mechanisms that generate and maintain those patterns. With understanding of mechanisms, one has predictive capacity that is impossible with correlations alone." The full circle of landscape analysis needs to be completed.

A fundamental challenge in landscape analysis today is to establish sound relationships between spatial pattern and ecological processes (Wu and Hobbs 2002). Specifically, great efforts are needed to address two critical questions: (1) how to use knowledge about spatial heterogeneity to improve explanations and predictions of ecological systems, and (2) how to scale up models and/or relationships across scales with aid of quantifying spatial heterogeneity at multiple scales. Spatial heterogeneity, scale, and scaling are among the most critical issues in ecology because they play significant roles in the sampling, analysis, and modeling to understand and predict ecosystem functions and dynamics (Wiens 1989; Brandt 1998; Turner et al. 2001; Wu 2003). Landscape analysis will not advance unless quantitative knowledge of spatial heterogeneity contributes to the ability to explain and predict and unless questions like "so what if a landscape has a contagion value of 1.45 " (or any other indices and values) are addressed directly and adequately. The extreme complexity and nonlinearity of heterogeneous landscapes engender high levels of uncertainty, making landscape dynamics difficult to predict. To reduce uncertainty and increase predictability, future research in landscape pattern analysis must go beyond the mere quantification of landscape pattern and emphasize its relationships to ecological processes.

\section{Acknowledgements}

HL and JW thank J. Brandt and anonymous reviewers for their critical, valuable comments on earlier drafts of the manuscript. HL is supported by USDA Forest Service Southern Research Station. JW would like to acknowledge the support from EPA grant R827676-01-0 and NSF grant DEB 97-14833 (CAPLTER). This paper has not been subjected to the Agencies' required peer and policy review and therefore does not necessarily reflect the views of the agencies and no official endorsement should be inferred.

\section{References}

Allen R.F.H., O’Neill R.V. and Hoekstra T.W. 1984. Interlevel relations in ecological research and management: Some working principles from hierarchy theory. USDA Forest Service General Tech Report RM-110, Rocky Mountain Forest and Range Experiment Station.

Bian L. and Butler R. 1999. Comparing effects of aggregation methods on statistical and spatial properties of simulated spatial data. Photogrammetric Engineering and Remote Sensing 65: 73-84.

Brandt J. 1998. Key concepts and interdisciplinarity in landscape ecology: a summing-up and outlook. In: Dover J.W. and Bunce R.G.H. (eds), Key Concepts in Landscape Ecology, pp. 421-434. UK Association of International Association for Landscape Ecology (IALE-UK), Garstang, Great Britain.

Cale W.G., Henebry G.M. and Yeakley J.A. 1989. Inferring process from pattern in natural communities. BioScience 39: 600605.

Carpenter S.R. 1992. Replication and treatment strength in wholelake experiments. Ecology 73: 453-463.

Carpenter S.R. 1996. Microcosm experiments have limited relevance for community and ecosystem ecology. Ecology 77: 453-463.

Dale M.R.T. 1999. Spatial Pattern Analysis in Plant Ecology. Cambridge University Press, Cambridge, UK.

Flather C.H. and Sauer J.R. 1996. Using landscape ecology to test hypotheses about large-scale abundance in migratory birds. Ecology 77: 28-35.

Gardner R.H., Milne B.T., Turner M.G. and O’Neill R.V. 1987. Neutral models for the analysis of broad-scale landscape pattern. Landscape Ecology 1: 19-28.

Gustafson E.J. 1998. Quantifying landscape spatial pattern: What is the state of the art? Ecosystems 1: 143-156.

Hamel P.B. 1992. The Land Manager's Guide to the Birds in the South. The Nature Conservancy, Chapel Hill, North Carolina, USA.

Haines-Young R. and Chopping M. 1996. Quantifying landscape structure: a review of landscape indices and their application to forested landscapes. Progress in Physical Geography 20: 418-445.

Hargis C.D., Bissonette J.A. and David J.L. 1998. The behavior of landscape metrics commonly used in the study of habitat fragmentation. Landscape Ecology 13: 167-186.

Hargrove W.W. and Pickering J. 1992. Pseudoreplication: A sine qua non for regional ecology. Landscape Ecology 6: 251-258. 
Harris L.D. and Sanderson J. 2000. The re-membered landscape. In: Sanderson J. and Harris L.D. (eds), Landscape Ecology: A Top-Down Approach, pp. 91-112. Lewis Publishers, Boca Raton, Florida, USA.

Hurlbert S.H. 1971. The nonconcept of species diversity: a critique and alternative parameters. Ecology 52: 577-586.

Hurlbert S.H. 1984. Pseudoreplication and the design of ecological field experiments. Ecological Monographs 54: 187-211.

Jelinski D.E. and Wu J. 1996. The modifiable areal unit problem and implications for landscape ecology. Landscape Ecology 11: 129-140.

Justice C.O., Markham B.L., Townshend J.R.G. and Kennard R.L. 1989. Spatial degradation of satellite data. International Journal of Remote Sensing 10: 1539-1561.

Krummel J.R., Gardner R.H., Sugihara G., O'Neill R.V. and Coleman P.R. 1987. Landscape patterns in a disturbed environment. Oikos 48: 321-324.

Levin S.A. 1992. The problem of pattern and scale in ecology. Ecology 73: 1943-1967.

Li H. and Reynolds J.F. 1993. A new contagion index to quantify spatial patterns of landscapes. Landscape Ecology 8: 155-162.

Li H. and Reynolds J.F. 1994. A simulation experiment to quantify spatial heterogeneity in categorical maps. Ecology 75: 24462455.

Li H. and Reynolds J. F. 1995. On definition and quantification of heterogeneity. Oikos 73: 280-284.

Li H., Gartner D., Mou P. and Trettin C.C. 2000. A landscape model (LEEMATH) to evaluate effects of management impacts on timber and wildlife habitat. Computers and Electronics in Agriculture 27: 263-292.

Lovejoy S. 1982. Area-perimeter relation for rain and cloud areas. Science 216: 185-187.

Ludwig J.A., Wiens J.A. and Tongway D.J. 2000. A scaling rule for landscape patches and how it applies to conserving soil resources in Savannas. Ecosystems 3: 84-97.

Milne B.T. 1991. Lessons from applying fractal models to landscape patterns. In: Turner M.G. and Gardner R.H. (eds), Quantitative Methods in Landscape Ecology, pp. 199-235. SpringerVerlag, New York, New York, USA.

Naveh Z. and Lieberman A.S. 1984. Landscape Ecology: Theory and Application. Springer-Verlag, New York, New York, USA.

Oksanen L. 2001. Logic of experiments in ecology: Is pseudoreplication a pseudoissue? Oikos 94: 27-38.

O’Neill R.V., DeAngelis D.L., Waide J.B. and Allen T.F.H. 1986. A Hierarchical Concept of Ecosystems. Princeton University Press, Princeton, New Jersey, USA.

O’Neill R.V., Krummel J.R., Gardner R.H., Sugihara G., Jackson B., DeAngelis D. L., Milne B.T., Turner M.G., Zygmunt B., Christensen S.W., Dale V.H. and Graham R.L. 1988. Indices of landscape pattern. Landscape Ecology 1: 153-162.

O’Neill R.V., Riitters K.H., Wickham J.D. and Jones K.B. 1999. Landscape pattern metrics and regional assessment. Ecosystem Health 5: 225-233.

Openshaw S. 1984. The Modifiable Areal Unit Problem. Geo Books, Norwich, UK.

Pickett S.T.A. and Cadenasso M.L. 1995. Landscape ecology: spatial heterogeneity in ecological systems. Science 269: 331-334.
Pickett S.T.A., Kolasa J. and Jones C.G. 1994. Ecological Understanding. Academic Press, San Diego, California, USA.

Risser P.G., Karr J.R. and Forman R.T.T. 1984. Landscape Ecology: Directions and Approaches. Illinois Natural History Survey Special Publ. 2, Champaign, Illinois, USA.

Riitters K.H., O’Neill R.V., Hunsaker C.T., Wickham J.D., Yankee D.H., Timmins K.B.J. and Jackson B.L. 1995. A factor analysis of landscape pattern and structure metrics. Landscape Ecology 10: 23-39.

Saura S. and Martinez-Millan J. 2001. Sensitivity of landscape pattern metrics to map spatial extent. Photogrammetric Engineering and Remote Sensing 67: 1027-1036.

Turner M.G. 1989. Landscape ecology: the effect of pattern on process. Annual Review of Ecology and Systematics 20: 171197.

Turner M.G. 1990. Spatial and temporal analysis of landscape pattern. Landscape Ecology 4: 21-30.

Turner M.G. and Gardner R.H. 1991. Quantitative Methods in Landscape Ecology: The Analysis and Interpretation of Landscape Heterogeneity. Springer-Verlag, New York, New York, USA.

Turner M.G., Gardner R.H. and O’Neill R.V. 2001. Landscape Ecology in Theory and Practice: Pattern and Process. Springerverlag, New York, New York, USA.

Turner M.G., O’Neill R.V., Gardner R.H. and Milne B.T. 1989. Effects of changing spatial scale on the analysis of landscape pattern. Landscape Ecology 3: 153-162.

Urban D.L., O’Neill R.V. and Shugart H.H. 1987. Landscape ecology: A hierarchical perspective can help scientists understand spatial patterns. BioScience 37: 119-127.

Wickham J.D. and Riitters K.H. 1995. Sensitivity of landscape metrics to pixel size. International Journal of Remote Sensing 16: 3585-3595.

Wickham J.D., O'Neill R.V., Riitters K.H., Wade T.G. and Jones K.B. 1997. Sensitivity of landscape metrics to land cover misclassification and differences in land cover composition. Photogrammetric Engineering and Remote Sensing 63: 397-402.

Wiens J.A. 1989. Spatial scaling in ecology. Functional Ecology 3: 385-397.

Wiens J.A., Stenseth N.C., Van Horne B. and Ims R.A. 1993. Ecological mechanisms and landscape ecology. Oikos 66: 369-380.

Wu J. 1999. Hierarchy and scaling: Extrapolating information along a scaling ladder. Canadian Journal of Remote Sensing 25: $367-380$.

Wu J. 2000. Landscape Ecology: Pattern, Process, Scale and Hierarchy. Higher Education Press, Beijing, China.

Wu J. 2004. Effects of changing scale on landscape pattern analysis: Scaling relations. Landscape Ecology 19: 125-138.

Wu J. and Hobbs R. 2002. Key issues and research priorities in landscape ecology: An idiosyncratic synthesis. Landscape Ecology 17: 355-365.

Wu J. and Loucks O.L. 1995. From balance-of-nature to hierarchical patch dynamics: A paradigm shift in ecology. Quarter Review of Biology 70: 439-466.

Wu J., Shen W. Sun W. and Tueller P.T. 2002. Empirical patterns of the effects of changing scale on landscape metrics. Landscape Ecology 17: 761-782. 